\section{0 caminho do pós-terror na crítica cinematográfica brasileira na internet}

\section{The post-terror path in Brazilian film criticism on the internet}

\section{Caroline de Aguiar}

Universidade Estadual de Campinas. Instituto de Computação.

\section{RESUMO}

Em um artigo para o The Guardian, Steve Rose usa pela primeira vez o termo pós-terror, referindo-se à nova leva de filmes de terror que quebram as regras do gênero. Pretendo traçar o caminho percorrido por esse termo na crítica cinematográfica brasileira na internet através da análise de dois artigos.

PALAVRAS-CHAVE: pós-terror, terror, gênero cinematográfico, crítica cinematográfica, crítica na Internet.

\section{ABSTRACT}

In an article written for the newspaper The Guardian, Steve Rose first uses the term post-horror, referring to the new wave of horror films that break the rules of the genre. I intend to trace the path taken by this term in Brazilian online film criticism through the analysis of two articles.

KEYWORDS: post-horror, horror, film genre, film criticism, online criticism.

\section{INTRODUÇÃO}

A crítica cinematográfica brasileira, cujas raízes estão na mídia jornalística tradicional, ganha cada vez mais espaço na internet, onde encontrou um espaço com maior liberdade. De acordo com Cruz (2013), a crítica cinematográfica no Brasil despontou na internet no final dos anos 1990, já que a própria internet só chegou ao público geral no país em 1995. Em 1997, mesmo com as dificuldades de velocidade e acesso, surge o site Cinema em Cena, criado pelo crítico Pablo Villaça. Já no ano seguinte, em 1998, é fundada a Contracampo, revista dedicada à crítica de cinema e importante título no meio, que estava disponível na internet. O baixo custo para a manutenção de um site e a facilidade que a internet tem de fomentar debates fizeram com que, a partir daí, a crítica no ambiente digital só crescesse e ganhasse cada vez mais seriedade. Carreiro (2009) afirma que a crítica cinematográfica vive um momento de expansão e transição, pois, enquanto a mídia clássica dedica um espaço cada vez menor à crítica, novos modelos e tendências têm surgido no ciberespaço. Segundo Cruz (2013), o estabelecimento da crítica na internet permitiu uma renovação no desenvolvimento da atividade. Devido à possibilidade de abordar públicos mais amplos, ao fato de poder se editar o texto quando e quantas vezes se quiser, à possibilidade de uma expressão mais independente, à inexistência de restrições editoriais relacionadas ao tamanho e à quantidade de textos, a crítica na internet ganhou características próprias que a diferenciam da crítica tradicional impressa.

A crítica cinematográfica brasileira na internet está longe de ser homogênea. Atualmente existem sites como o "Adoro Cinema" e o "Omelete", que trazem críticas de filmes, mas que têm um perfil mais comercial, com espaços destinados à propaganda, e que se baseiam em um cinema mainstream. Ambos seguem a linha do jornalismo cultural, tendo notícias e conteúdos variados em torno da temática do cinema. O "Omelete", inclusive, não se restringe somente ao cinema, falando 
também sobre cultura pop, jogos, música e séries de televisão. O "Adoro Cinema" traz um fichamento dos filmes, semelhante ao realizado pelo site norte-americano IMDB. As fichas dos filmes contêm informações como data de lançamento, elenco, curiosidades sobre a produção, fotos, trailers, notas do filme dadas pelos críticos dos principais jornais, além de críticas escritas pelos próprios usuários do site.

Em oposição total a esses sites, estão "Contracampo", "Cinética" e as demais revistas da chamada "nova crítica", que foram influenciadas pela revista francesa "Cahiers du Cinéma". Esses periódicos trazem em suas edições online críticas mais próximas do âmbito acadêmico e longe do cinema mainstream. Há também uma crítica mais tradicional, composta pelo "Cinema em Cena" e as colunas sobre cinema nos sites de jornais impressos como "O Globo", "Estadão" etc. E por fim existe uma crítica mais alternativa e independente, formada pelo "Cinema com Rapadura", "Revista Moviement", "Quinquilharia", entre muitos outros. São sites criados por pessoas que, unidas pelo seu interesse em cinema, escrevem e debatem sobre o assunto.

O objetivo deste artigo é descrever o caminho do pós-terror na crítica cinematográfica brasileira na internet. Para atingir este objetivo, decidi fazer uma extensa pesquisa na internet e escolher artigos para serem analisados. Utilizei a ferramenta de pesquisa de cada site ("Adoro Cinema", "Omelete", "Contracampo", "Cinética” etc.) procurando pelos termos "pós-terror" e termos semelhantes ("terror inteligente", "terror sério", "terror sofisticado"). Também pesquisei simplesmente pela palavra "terror" e li os textos com esse termo para confirmar se realmente minha pesquisa dentro dos sites estava completa. Por fim, utilizei o "Google", já que é comum que o sistema de pesquisa dentro dos sites não ser tão eficiente quanto o próprio "Google". Procurei pelos mesmos termos e pelos termos acompanhados dos nomes dos sites e das revistas eletrônicas ("pós-terror Contracampo", "terror inteligente Adoro Cinema" etc.)
Após ter feito esta pesquisa aprofundada, obtive os seguintes resultados. Como era de se esperar, por serem mais comerciais, "Adoro Cinema" e "Omelete" fizeram menção ao pós-terror em apenas um texto e tardiamente. No artigo "A era do pósterror: a problemática segregação de um gênero consolidado", publicado em 21 de setembro deste ano no "Adoro Cinema", Palopoli (2019) faz uma rápida análise sobre o novo gênero. Escrevendo de uma forma didática, o autor entende o pós-terror como uma questão bem problemática, assim como a maioria dos que escreveram sobre o tema, já que o terror psicológico existe há anos e houve diversos filmes de terror que quebraram com os padrões, mas só agora foi considerado um gênero. Ele também vê o termo pós-terror como uma muleta que os críticos vêm se utilizando quando falham em encontrar definições para filmes de terror com propostas diferentes. Palopoli (2019) faz um resumo bom, porém tardio, de todas as ideias já discutidas sobre o assunto por outros autores.

"Continuando", "Contracampo" e "Cinética", espantosamente, não mencionam o termo. A crítica tradicional, "Folha de S. Paulo" e "Correio Braziliense", fizeram textos sobre o pós-terror, porém eram textos bem neutros e descritivos. Já a crítica alternativa se debruçou bem mais no assunto.

Após a leitura de todos os artigos resultantes da minha consulta, percebi que os textos podem ser divididos em 3 categorias: 1) textos jornalísticos descritivos sem opiniões expressas dos autores; 2 ) artigos que apontam discrepâncias no uso do termo "pósterror", mas que creditam isso ao fato de a classificação de filmes em gêneros e subgêneros, especialmente tratando-se do terror, ser complicada e divergente; e 3) artigos que criticam de forma pungente o termo inventado por Rose, apontando o elitismo e preconceito que esse conceito invoca.

Considerando que a primeira categoria mal se configura como crítica e que, portanto, não acrescentaria em nada para esta análise, optei por escolher dois textos das 
categorias restantes para fazer minha análise. Minha escolha não foi arbitrária. Esses dois textos são os mais exemplares de cada categoria, além de serem mais profundos na análise do pós-terror.

Através da análise e reflexão dos artigos Considerações sobre o tal do "pós-horror" (categoria 1), escrito pelo Calebe Lopes para a "Revista Moviement" e "Pós-terror" ou simplesmente "terror"? (categoria 2), escrito pela Bhárbara Andrade para o Quinquilharia, espero conseguir apontar como se deu a recepção desse novo termo - pós-terror - na crítica de cinema brasileira na internet. Mas o que é e onde surgiu o termo pós-terror?

\section{O PÓS-TERROR}

Em um artigo escrito em 06 de julho de 2017 para a versão online do jornal britânico The Guardian, o jornalista Steve Rose usa pela primeira vez o termo pós-terror. Em pouco mais de 1700 palavras, Rose (2017) se utiliza do filme "Ao Cair da Noite "(It Comes at Night, Trey Edward Shults, 2017) para fazer uma análise sobre a nova leva de filmes de terror que, segundo ele, quebram as regras dos filmes do gênero.

"Ao Cair da Noite" conta a história de Paul, sua esposa Sarah, seu filho de dezessete anos Travis e seu sogro Bud. O filme começa com os personagens vivendo uma vida reclusa em uma cabana isolada na floresta, quando Bud contrai uma doença misteriosa e a família é forçada a matá-lo e queimar seu corpo. Após isso, durante uma noite, um invasor entra na casa. A família domina o homem, deixando-o amarrado a uma árvore em quarentena para saber se ele está doente ou não. Alguns dias depois eles chegam à conclusão de que o estranho é saudável e resolvem soltá-lo. O homem explica que deixou sua esposa e seu filho em uma casa abandonada para procurar por água e comida. Paul e Sarah o convidam a trazê-los para morar com eles, para que possam proteger uns aos outros. Na chegada dos novos moradores, Paul explica as regras de sua casa e todos compartilham o trabalho e os suprimentos. Mas a paranoia sobre a doença e a ameaça externa chegam à casa afetando a vida das duas famílias. O filme obteve sucesso com a crítica especializada, porém foi um fracasso com o público em geral, com muitas críticas negativas. Rose (2017) atribui isso ao fato da película possuir todos os elementos indicativos de um filme de terror convencional, “cenário pós-apocalíptico, uma cabana na floresta, máscaras de gás, espingardas, prisioneiros, um patriarca severo, e avisos para nunca deixar as portas destrancadas ou sair à noite" (ROSE, 2017, tradução nossa), mas na verdade ser uma obra que quebra as regras clássicas do gênero, o que acaba não agradando boa parte dos espectadores, que não estão acostumados com isso. O trailer do filme, inclusive, contribui para esse equívoco, sugerindo que há um monstro escondido atrás de uma misteriosa porta vermelha ou que o seu mote principal seja uma praga que infecta uma família. Realmente, esses elementos estão presentes, mas são, em última análise, maneiras de destilar um filme complexo, cheio de ideias, em algo mais simples e palatável. "Ao Cair da Noite" aborda o horror como uma estrutura, usando-o para construir um drama psicológico sobre a família, a violência e a dor da adolescência. Cherry (2009) explica isso afirmando que alguns filmes podem ser colocados em categorias comercializáveis que podem ser vendidas para o público, mas sem se encaixar exatamente na fórmula.

Essa estratégia - colocar filmes em categorias comercializáveis, ou seja, gêneros - tem fundamento. Suas raízes estão no studio system. Segundo Schatz (1981), durante o reinado do studio system, filmes de gênero compreendiam a grande maioria das produções mais populares e rentáveis, e essa tendência continuou mesmo após a sua morte. Em contrapartida, filmes não-gênero conseguiam atrair maior atenção da crítica durante a era do estúdio.

Rose (2017) então cria um novo subgênero para classificar esses filmes que quebram 
as regras do gênero "substituindo jump-scares com medo existencial" (ROSE, 2017, tradução nossa) e o batiza de pós-terror. O escritor estrutura seu raciocínio argumentando que, considerando que o terror explora nossos medos, tanto mortais quanto sociais, o gênero em si é um dos mais seguros de se trabalhar, o que faz com que este, mais do que qualquer outro gênero, seja comando por regras e códigos claros. E o que ele chama de pós-terror nada mais é do que jovens diretores fazendo filmes de terror sem seguir essas regras e códigos. O escritor também deixa claro que ao quebrar essas regras podemos encontrar algo mais assustador ou, pelo contrário, algo nada assustador. É um jogo arriscado.

O próprio diretor e roteirista de "Ao Cair da Noite", o jovem Trey Edward Shults, relata que não se propôs fazer um filme de terror por si só, apenas quis fazer algo pessoal e acabou colocando seus próprios medos em sua obra cinematográfica. Ele inclusive concorda com o fato de "Ao Cair da Noite "não ser um filme convencional do gênero. Shults pesquisou sobre genocídios e ciclos sociais de violência para fazer o filme, mas ele cita a morte do pai, que aconteceu um pouco antes dele escrever o roteiro, como principal desencadeador da sua ideia para o filme. Seu pai tinha um histórico de vício e confessou no seu leito de morte estar arrependido de algumas decisões que tomou durante a vida. E é isso que Shults explora em seu longa-metragem: a morte, a incerteza sobre o que vem depois dela, mas, sobretudo, o remorso e arrependimento das decisões tomadas em vida.

Shults também diz que foi influenciado por Roman Polanski. Rose (2017) então cita a trilogia do apartamento - "Repulsa ao Sexo" (Repulsion, Roman Polanski, 1965), "O Bebê de Rosemary" (Rosemary's Baby, Roman Polanski, 1968) e"O Inquilino" (Le Locataire, Roman Polanski, 1976) e -, além de "Inverno de Sangue em Veneza" (Don't Look Now, Nicolas Roeg, 1973) e "O Iluminado" (The Shining, Stanley Kubrick, 1980), como exemplos de "exercícios semelhantes em remodelar tropos de terror com uma sensibilidade de autor" (ROSE, 2017, tradução nossa). Porém, segundo ele, estes filmes se diferenciam de "Ao Cair da Noite" pois foram realizados em uma época onde os estúdios de terror tinham bastante recursos, diferente de Shults que teve que fazer seu filme com um orçamento bem mais modesto. Com isto, podemos desprender que, na visão de Rose (2017), o pós-terror não é só definido pelo conteúdo e quebra de códigos do terror convencional, mas também pela época e orçamento com que foram feitos.

Rose (2017) discorre sobre outros filmes recentes que podem se encaixar no pósterror. "A Bruxa" (The Vitch: A New-England Folktale, Robert Eggers, 2015), assim como a obra de Shults, tem título e trailer que sugerem um terror convencional, porém apresenta pouquíssimos sustos e explicações, obtendo sucesso com a crítica especializada, mas fracasso com o público em geral. "Personal Shopper" (Olivier Assayas, 2016), que acrescenta pequenos elementos sobrenaturais na história de uma assistente de moda que está procurando algum sinal de seu irmão morto, e "Demônio de Neon" (The Neon Demon, Nicolas Winding Refn, 2016), com supermodelos vampiras sedentas de sangue, são também exemplos do pós-terror.

Mas para Rose (2017), o filme que mais representa o pós-terror é "Sombras da Vida" (A Ghost Story, David Lowery, 2017). O título do filme traz algumas expectativas. Existe um fantasma, mas é apenas uma pessoa coberta com um lençol branco. Esse personagem morreu em um acidente de carro e vaga pela casa de sua esposa, sem que ela o consiga ver. Ela se muda e ele acaba ficando preso ao local, para sempre. "O tempo faz um loop em si mesmo, e a história se expande do trauma pessoal para os reinos da especulação cósmica" (ROSE, 2017, tradução nossa).

O diretor e roteirista de "Sombras da Vida", David Lowery, quis colocar em sua obra os arquétipos e a iconografia de filmes de fantasmas e filmes de casa mal-assombrada, sem nunca passar a ser realmente um filme de terror, pelo menos não um dos 
convencionais. Ele conta que estava tendo uma crise existencial geral sobre o seu lugar no universo, e ao mesmo tempo estava tendo um conflito muito pessoal com sua esposa sobre para onde iriam se mudar. Essa situação de angústia e ansiedade pessoal do diretor acabou ditando como seria a obra. O filme também teve um orçamento modesto. Lowery fez este filme com os lucros de seu filme anterior, uma aventura da Disney.

É também ressaltado por Rose (2017) o fato que "Ao Cair da Noite", "A Bruxa" e "Sombras da Vida" foram distribuídas pela mesma empresa: A24. A A24 é uma empresa jovem que já obteve grande sucesso no Oscar com "Moonlight: Sob a Luz do Luar" (Moonlight, Barry Jenkins, 2016) e "O Quarto de Jack" (Room, Lenny Abrahamson, 2015). Para o escritor a A24 está alavancando o pós-terror como ninguém.

Se alguém está empurrando o terror para novos reinos, são eles, mas não é hora? Sempre haverá um lugar para os filmes que nos reatualizam com nossos medos primordiais e nos assustam. Mas quando se trata de abordar as grandes questões metafísicas, o quadro de horror corre o risco de ser demasiado rígido para apresentar novas respostas - como uma religião moribunda. Espreitando um pouco além do seu cordão está um vasto nada negro, esperando que brilhemos nele. (ROSE, 2017, tradução nossa)

Rose (2017) ainda revela que terror é o gênero mais rentável na indústria cinematográfica, e está crescendo. Ele cita números de longas de terror que fizeram sucesso no ano de 2017, "Corra!" (Get Out, Jordan Peele, 2017) e "Fragmentado" (Split, M. Night Shyamalan, 2017), e que, como resultado, surge um mercado para filmes de terror apelativos e de baixo orçamento, o que basicamente significa obras com as temáticas de possessão demoníaca, casa mal-assombrada, psicopatas e zumbis, com todas as regras e códigos convencionais do gênero. E este, de acordo com Rose (2017), é o mercado que o pós-terror está reagindo contra.

\section{CONSIDERAÇÕES SOBRE O TAL DO “PÓS-HORROR”}

Apenas uma semana após Steve Rose divulgar seu texto no The Guardian, o escritor Calebe Lopes resolveu escrever suas considerações sobre o pós-terror na Revista Moviement, site que funciona como uma vitrine de textos de diversas pessoas que resolveram se unir para compartilhar o que sabem sobre cinema, debatendo sobre produção audiovisual no Brasil e no mundo. Lopes (2017) trata o pós-terror como uma tentativa de rotular um movimento que vem acontecendo dentro do gênero de terror, onde filmes independentes se arriscam fugindo das convenções do terror, e, por isso, não são bem recebidos pelo grande público. E Rose "na ânsia de fazer história batizando certo gênero/movimento - assim como Grierson, ao criticar "Moana" (1926, Robert Flaherty), nomeou aquele tipo de filme como "documentário" —, resolveu catalogar essa nova inclinação como 'pós-horror'" (LOPES, 2017).

Lopes (2017) resolve fazer um resumo sobre o queé terror, dizendo que este nada mais é que o gênero sobre o medo, podendo ser tanto o medo que os personagens da obra sentem, como o medo que o público é levado a sentir. Para Odell e Le Blanc (2007), o principal propósito do gênero de terror também é causar medo no espectador. Existe uma espécie de catarse no terror, já que o público vê os personagens lidarem com situações aterrorizantes, pior do que qualquer uma que ele enfrentaria no dia-adia, e saem ilesos do cinema. Não é um gênero somente para dar sustos ou derramar sangue, mas que pode se utilizar disso para causar medo.

Lopes (2017) continua seu raciocínio, dizendo que o gênero é marcado por movimentos, funcionando por meio de ciclos, que determinam as regras e códigos que o gênero terá durante um período de tempo. Como exemplos, ele cita os anos 1980 que são conhecidos pela ebulição do subgênero slasher, o qual foi influenciado por outro movimento: o giallo dos anos 1970. E, no momento atual, o cinema de terror se divide entre os filmes comerciais que repetem o que já foi feito com James 
Wan talvez sendo seu maior representante; e os filmes independentes, feitos por cineastas jovens, que se permitem subverter e brincar com os clichês do gênero, apropriando-se de seus códigos para construírem algo diferente. Estes cineastas estão "muito mais interessados na experimentação da linguagem cinematográfica do que o comprometimento com as formalidades do nicho" (LOPES, 2017).

Lopes (2017) cita os filmes de terror de Jacques Tourneur na década de 1940 e "Inverno de Sangue em Veneza", também mencionado por Rose em seu texto, como exemplos de filmes que já se apropriavam de códigos do gênero da mesma maneira que o pós-terror, só que muitos anos antes. Portanto, “o pós-terror nada mais é do que filmes de terror que buscam quebrar com os clichês, tendência essa que sempre surge quando determinado gênero satura, e que não é inédita" (LOPES, 2017).

Lopes (2017) afirma que mesmo que a nomenclatura pareça equivocada - já que os filmes, ainda que arrisquem traços autorais e quebras de códigos, não são uma exclusividade dos nossos tempos —-, Rose está apenas tentando classificar mais um padrão que vem surgindo no gênero. E realmente, a definição de pós-terror como sendo um subgênero parece estar um pouco desacertada.

De acordo com Cherry (2009) deveria ser fácil definir um gênero por seu conjunto distintivo de características, enredos estereotipados e estilo visual identificável. No entanto, isso não é tão verdadeiro quanto se trata do gênero terror, evidenciado pela grande variedade de personagens, eventos narrativos e estilos. Mas dado que os gêneros cinematográficos se destinam a ser categorias descritivas baseadas em traços comuns compartilhados, como tantos filmes diferentes de terror podem ser contidos tanto por concepções populares quanto acadêmicas de gênero? No terror não há características tão bem definidas como existem em outros gêneros, muito pelo contrário, esse gênero é marcado por uma diversidade de convenções, parcelas e estilos.
Para Cherry (2009) a chave para a grande diversidade do gênero de terror talvez sejam sua longevidade - desde os primeiros anos de cinema até os dias atuais - e o fato de derivar de tantas fontes diferentes, o que acabou o fragmentando em um conjunto extremamente diversificado de subgêneros. Cherry (2009) define subgêneros como categoria que dividem o todo ao longo de linhas de tramas, assuntos ou tipos de monstros. Usando essa definição, o pós-terror dificilmente poderia ser considerado um subgênero, já que seus enredos e assuntos são muito diferentes, e a única coisa que os une é a quebra de códigos e regras do terror tradicional.

Talvez o pós-terror se encaixe melhor na definição de ciclo: "grupo de filmes feitos dentro de um período limitado de tempo que exploram as características de um filme comercialmente bem-sucedido" (NEALE, 2000, tradução nossa). As características em comum não são de as um filme comercialmente bem-sucedido, mas sim a quebra de regras e códigos, o aspecto autoral, o orçamento escasso e o terror psicológico e metafísico. O período de tempo é o atual e, apesar de existirem filmes de muitos anos atrás que pudessem ser considerados como pós-terror, estes eram exceções de sua época, e não uma tendência como se mostra agora.

E se pensarmos que toda a teoria de gêneros nasceu devido ao studio system e a partir de regras estritas que filmes deveriam seguir para se tornarem um sucesso de público, chamar o pós-terror de subgênero passa a fazer menos sentido ainda. Categorizar filmes que quebram as regras dos filmes de um gênero já estabelecido e que fazem sucesso apenas com a crítica especializada como um subgênero é quase um paradoxo. O pós-terror pode ser considerado, por um lado, como uma negação do gênero de terror.

Mas para Lopes (2017), o problema não vem da teoria, mas da prática. Independente da tentativa de rotulação de Rose estar correta ou não, existe um público que está habituado aos clichês do terror, e quando vai ao cinema espera encontrá-los. "Mais 
do que qualquer outro gênero, o terror sempre se torna refém desses clichês, e quando há a quebra dos mesmos, sempre há polêmica e decepção por parte do grande público." (LOPES, 2017). O escritor acredita que as pessoas que vão ao cinema para ver filmes de terror não vão com o objetivo de ver um bom filme. Esse público está mais interessado em levar sustos e rir de nervoso, acreditando que essa seja a maior experiência que aquele produto possa lhe oferecer. E Lopes (2017) usa a palavra produto com razão, já que a maioria dos filmes de terror produzidos são extremamente comerciais, com muitos jump-scares e pouca preocupação com os outros aspectos que compõem uma obra-cinematográfica. Estão mais interessados em fazer algo que agrade o público, e que, consequentemente, obtenha muito lucro. Sendo assim, filmes que apostam em uma atmosfera de medo e que entregam poucos sustos, são considerados péssimos filmes de terror por um público despreparado.

No todo, Lopes (2017) aponta algumas inconsistências no artigo e no termo criado por Rose, mas releva isso devido ao fato de classificações no gênero de terror serem extremamente difíceis e problemáticas. Lopes (2017) decide focar mais na explicação do que é o terror e por que o público não se agradou com filmes como "A Bruxa" e "Ao Cair da Noite".

\section{“PÓS-TERROR” OU SIMPLESMENTE “TERROR”?}

Pouco mais de um mês depois da publicação do artigo de Steve Rose, Bhárbara Andrade discorre sobre o pós-terror em um pequeno artigo para o Quinquilharia, grupo que se auto intitula como mídia alternativa e cuja atuação ocorre somente na internet. Andrade (2017) questiona, em seu texto, se o pós-terror realmente "aponta para algo diferente do tradicional gênero terror" (ANDRADE, 2017).

A escritora afirma que os filmes citados por Rose - "Ao Cair da Noite", "A Bruxa", "Personal Shopper", "Sombras da Vida" - têm em comum o terror psicológico, questões profundas e metafísicas, além de uma grande rejeição do público, que não aprovou os longos silêncios destes filmes. Andrade (2017) ainda argumenta que, pelos parâmetros usados por Rose, filmes clássicos como "O Bebê de Rosemary" (POLANSKI, 1969) e "O lluminado" (KUBRICK, 1980) se encaixariam no pós-terror, demonstrando que, muito antes da criação desse termo, já existiam filmes que traziam temas muito mais abstratos e profundos.

No artigo, Andrade (2017) fala que existe um problema de semântica no termo pósterror. A autora afirma que a preposição "pós" é usada para se referir a algo que se distancia ou rejeita aquilo que veio antes, ou simplesmente algo que veio depois de. Sendo assim, o pós-terror teria que ser uma negação do terror - o que não é - ou uma nova forma de expressar o terror como se este fosse ultrapassado e precisasse ser substituído. Mas sabemos que o chamado pós-terror é mais uma tentativa de modificar o gênero terror, e não uma negação total do gênero. Este subgênero pode até negar as regras e códigos do terror, mas ainda se utiliza, e muito, dos seus elementos.

Andrade (2017) acusa Rose de ser esnobe com o gênero de terror, assim como a Academia de Artes e Ciências Cinematográficas, responsável pelo Oscar, ignora em suas indicações excelentes filmes de terror, como "A Bruxa". Realmente, segundo Odell e Le Blanc (2007), o filme de terror tem uma reputação assustadora, sendo rejeitado pelos críticos e ridicularizado pela mídia, porém é imensamente popular, diversificado em conteúdo e tão antigo quanto o próprio cinema.

O horror, em sua maior parte, continua sendo a província do aficionado e não do crítico, com críticas positivas geralmente justificadas pela reclassificação do produto - é improvável que você encontre obras de Bergman, Pasolini ou Buñuel na seção de terror de sua loja local de DVDs, apesar do fato de todos eles terem feito filmes de terror. Mas sua contínua popularidade sugere que as pessoas vão se desfazer de 
seu tempo e dinheiro, novamente, pelo privilégio de ficarem assustadas sem saber o que fazer. (ODELL; LE BLANC, 2007, p.13, tradução nossa)

Certas atitudes como a do ator Jamie Lee-Hill, que postou um tweet acompanhado da hashtag \#elevatedhorror (algo como "terror sofisticado", em tradução livre) após a estreia do curta-metragem "A Still Sunrise" (lakovos Panagopoulos, 2018) no Festival de Cannes em 2018, no qual atua, e ao ser perguntado por que usou esse termo em particular, responde que é porque o curta é realmente um drama inteligente com simbolismos dentro do filme, mostram que o preconceito com o gênero de terror é algo real.

John Krasinski, co-roteirista e diretor de "Um Lugar Silencioso" (A Quiet Place, John Krasinski, 2018), afirmou em uma entrevista que sua obra não foi inspirada em filmes comuns de terror, mas em filmes extraordinários de terror sofisticado, uma referência clara aos filmes de pós-terror citados por Rose. Sempre que um filme de terror faz sucesso, há invariavelmente um artigo classificando-o de horror inteligente, sofisticado ou cult. Os termos "terror sofisticado", "pós-terror", "terror inteligente", "terror sério" não agradam em nada os entusiastas do gênero de terror, que os consideram um desprezo paternalista e reducionista do gênero que veneram. A crítica não usa termos como "dramas sofisticados" para diferenciar os filmes desse gênero.

Andrade (2017) termina seu texto afirmando que Rose fez um desfavor ao terror ao criar o subgênero pós-terror, que nada mais é que uma maneira de dizer que filmes de terror mais profundos não merecem ser classificados como tal. No geral, Andrade (2017) faz diversas ressalvas ao pós-terror e rechaça a tentativa de classificação de Rose.

\section{CONCLUSÃO}

Como já dito antes, a crítica cinematográfica brasileira na internet está longe de ser homogênea, assim como foi a recepção desta ao novo termo pós-terror. Como era de se esperar, por serem mais comerciais, sites como o Adoro Cinema e Omelete não fizeram nenhuma menção ao pós-terror em seus textos. Contracampo e Cinética, espantosamente, também não mencionaram o termo. Já a crítica tradicional, Folha de S. Paulo e Correio Braziliense, fizeram textos sobre o pós-terror, porém eram textos bem neutros e descritivos, e que não acrescentaram em nada para esta análise. Já a crítica alternativa se debruçou bem mais no assunto.

Os dois textos analisados neste artigo - "Considerações sobre o tal do "pós-horror"', escrito pelo Calebe Lopes para a Revista Moviement e "“'Pós-terror" ou simplesmente "terror"?", escrito pela Bhárbara Andrade para o Quinquilharia -, ambos de sites de crítica alternativa e independente, conseguiram apontar de que forma se deu a recepção desse novo termo - pós-terror - na crítica de cinema brasileira na internet. Neste âmbito da crítica, o pós-terror não foi bem recebido ou recebido com muitas ressalvas. Andrade (2017) considera o termo como sendo preconceituoso para com o terror, além de apontar a problemática com a semântica da expressão criada. Já Lopes (2017) afirma que mesmo que a nomenclatura pareça equivocada, Rose está apenas tentando classificar mais um padrão que vem surgindo no gênero. Mas os dois concordam que a crítica possui, historicamente, certo preconceito com o gênero e as classificações no gênero de terror realmente são bem difíceis e polêmicas.

Decidir sobre uma classificação quanto a qual filme (ou tipo de filme) é (ou não) um filme de terror não é algo direto: de acordo com Jancovich (2002), o que pode ser classificado como as convenções essenciais do terror a uma geração pode ser muito diferente da próxima, e o que uma pessoa considera como características definidoras de um filme de terror pode estar em total desacordo com a classificação de outra 
pessoa. Talvez, no futuro, o pós-terror seja mais aceito e até usado oficialmente como uma classificação para essa série de filmes de terror que 2017 nos trouxe.

Assim, em vez de pensar no terror como um conjunto distinto e unificado de filmes com convenções compartilhadas, o gênero talvez deva ser mais precisamente pensado como um conjunto de categorias conceituais que se sobrepõem e evoluem e que estão em constante estado de fluxo. Simplificando, o terror não é um gênero, mas vários. Além disso, à medida que esses vários subgêneros mudam, os limites do gênero mudam também.

Para Cherry (2009), a função do terror - assustar, chocar, revoltar ou horrorizar o espectador - também significa que os cineastas estão constantemente forçando os limites do gênero para inventar novas maneiras de despertar essas emoções em suas audiências - que, com o tempo, naturalmente aprenderão o que esperar de um tipo específico de filme de terror, em um processo que pode levar os telespectadores a se acostumarem com a fórmula e enjoarem dela. De todas essas maneiras, noções sobre o gênero de terror estão constantemente mudando, criando novas categorias conceituais para continuar assustando o público.

\section{REFERÊNCIAS}

ANDRADE, Bhárbara. 'Pós-terror' ou simplesmente 'terror'? Quinquilharia, 14 de ago. de 2017. Disponível em: <https://grupoquinquilharia.com.br/site/pos-terrorou-terror/>. Acesso em: 30 de maio de 2019.

CARREIRO, Rodrigo. História de uma crise: a crítica de cinema na esfera pública virtual. Contemporânea, n., p.01-15, dez. 2009.

CHERRY, Brigid. Horror. Londres: Routledge, 2009.

CRUZ, Álvaro André Zeini. A crítica cinematográfica na internet. 2013. Dissertação (Mestrado em Multimeios) - Instituto de Artes, Universidade Estadual de Campinas,
Campinas. Disponível em: <http://www.repositorio.unicamp.br/bitstream/ REPOSIP/284512/1/ZeiniCruz_AlvaroAndre_M.pdf>. Acesso em:30 de maio de 2019.

LOPES, Calebe. Considerações sobre o tal do "pós-horror". Revista Moviement, 13 de jul. de 2017. Disponível em: <https://revistamoviement.net/ considera\%C3\%A7\%C3\%B5es-sobre-o-tal-p\%C3\%B3s-horror-58e329347188>. Acesso em: 30 de maio de 2019.

JANCOVICH, Mark. Genre and the audience: genre classifications and cultural distinctions in the mediation of the silence of the lambs. In: JANCOVICH, Mark. (Ed.). Horror The Film Reader. Londres: Routledge, 2002.

NEALE, Stephen. Genre and Hollywood. Londres: Routledge, 2000.

ODELL, Colin; LE BLANC, Michelle. Horror Films. Reino Unido: Kamera Books, 2007. PALOPOLI, Ygor. A era do pós-terror: A problemática segregação de um gênero consolidado. Adoro Cinema, 21 de set. de 2019. Disponível em: < http://www. adorocinema.com/noticias/filmes/noticia-150850/>. Acesso em: 30 de nov. de 2019. ROSE, Steve. How post-horror movies are taking over cinema. The Guardian, Londres, 6 de jul. de 2017. Disponível em: <https://www.theguardian.com/film/2017/jul/06/ post-horror-films-scary-movies-ghost-story-it-comes-at-night>. Acesso em: 30 de maio de 2019.

SCHATZ, Thomas. Hollywood Genres. Nova lorque: Random House, 1981.

\section{FILMES}

A BRUXA. Direção de Robert Eggers. Roteiro: Robert Eggers. EUA e Canadá: Parts and Labor, 2015. (92 min.), son., color.

AO CAIR da Noite. Direção de Trey Edward Shults. Roteiro: Trey Edward Shults. EUA: A24, 2017. (91 min.), son., color.

A STILL Sunrise. Direção de lakovos Panagopoulos. Roteiro: Andy Chapman. Reino 
Unido, 2017. Son., color.

CORRA!. Direção de Jordan Peele. Roteiro: Jordan Peele. EUA: Blumhouse Productions,

2017. (204 min.), son., color.

FRAGMENTADO. Direção de M. Night Shyamalan. Roteiro: M. Night Shyamalan. EUA: Blinding Edge Pictures, 2016. (217 min.), son., color.

INVERNO de Sangue em Veneza. Direção de Nicolas Roeg. Roteiro: Allan Scott e Chris Bryant. Reino Unido e Itália: Casey Productions, 1973. (110 min.), son., color.

MOONLIGHT: Sob a Luz do Luar. Direção de Barry Jenkins. Roteiro: Barry Jenkins e Tarell Alvin Mccraney. EUA: A24, 2016. (111 min.), son., color.

O INQUILINO. Direção de Roman Polanski. Roteiro: Gérard Brach e Roman Polanski. França: Marianne Productions, 1976. (126 min.), son., color.

O BEBÊ de Rosemary. Direção de Roman Polanski. Roteiro: Roman Polanski. EUA: William Castle Productions, 1968. (137 min.), son., color.

OILUMINADO. Direção de Stanley Kubrick. Roteiro: Stanley Kubrick e Diane Johnson. EUA e Reino Unido: Hawk Films, 1980. (146 min.), son., color.

O QUARTO de Jack. Direção de Lenny Abrahamson. Roteiro: Emma Donoghue. EUA, Canadá, Irlanda e Reino Unido: Filmnation Entertainment, 2015. (118 min.), son., color. PERSONAL Shopper. Direção de Olivier Assayas. Roteiro: Olivier Assayas. França, Alemanha, República Tcheca e Bélgica: CG Cinéma, 2016. (105 min.), son., color.

REPULSA ao Sexo. Direção de Roman Polanski. Roteiro: Roman Polanski e Gérard Brach. Reino Unido: Compton Films, 1965. (105 min.), son., P\&B.

SOMBRAS da Vida. Direção de David Lowery. Roteiro: David Lowery. EUA: Sailor Bear, 2017. (92 min.), son., color.

UM LUGAR Silencioso. Direção de John Krasinski. Roteiro: Bryan Woods, Scott Beck e John Krasinski. EUA: Platinum Dunes, 2018. (90 min.), son., color. 